\title{
Educação holística para o empreendedorismo: uma estratégia de desenvolvimento integral, de cidadania e cooperação
}

CRISTINA PINTO ALBUQUERQUE Universidade de Coimbra, Coimbra, Portugal

JOSÉ SOARES FERREIRA Associação para o Desenvolvimento Económico, Social e Humano, Lisboa, Portugal

GRAÇA BRITES Instituto Universitário de Lisboa, Lisboa, Portugal

\section{RESUMO}

$\mathrm{O}$ artigo procura posicionar a educação para o empreendedorismo como um elemento estratégico na promoção de modelos de desenvolvimento mais inclusivos, éticos e holísticos. Para o efeito, questiona as abordagens tradicionais associadas ao treino de competências funcionais e padronizadas em prol de uma noção de pedagogia empreendedora associada à capacitação e à educação para a cidadania $\mathrm{e}$ para o exercício de uma liberdade substancial e responsável. Por fim, procura ilustrar tais pressupostos com base na aplicação do Modelo Tree, por nós desenvolvido, a diversas situações reais de aprendizagem em contextos escolares.

\section{PALAVRAS-CHAVE}

educação; educação holística; empreendedorismo; desenvolvimento; cooperação. 


\title{
HOLISTIC EDUCATION FOR ENTREPRENEURSHIP: A STRATEGY FOR COMPREHENSIVE DEVELOPMENT, CITIZENSHIP AND COOPERATION
}

\author{
ABSTRACT \\ The paper seeks to position entrepreneurship education as a strategic element \\ in fostering development models more inclusive, holistic and ethical. To this \\ end it questions the traditional approaches associated with functional and \\ standardized skills training, towards a notion of entrepreneurial pedagogy \\ associated with capacitation and education for citizenship and for the \\ exercise of a substantial and responsible freedom. At the end it tries to \\ illustrate such assumptions from the application of the Tree Model, develop \\ by us, to several real learning situations in school environments.
}

\section{KEYWORDS}

education; holistic education; entrepreneurship; development; cooperation.

\section{EDUCACIÓN HOLISTICA PARA EL EMPRENDEDURISMO: UNA ESTRATEGIA PARA EL DESARROLLO INTEGRAL, LA CIUDADANÍA Y LA COOPERACIÓN}

\section{RESUMEN}

El artículo tiene como objetivo posicionar a la educación para el emprendedurismo como elemento estratégico en la promoción de modelos de desarrollo más incluyentes, éticos y holísticos. Para tal fin, pone cuestiones relacionadas con la formación y las habilidades funcionales estandarizadas de enfoque tradicional hacia una noción de pedagogía emprendedora vinculada a la formación y la educación para la ciudadanía y el ejercicio de la libertad responsable y sustancial. Al final intenta ilustrar tales supuestos con la aplicación del Modelo de Árbol, desarrollado por nosotros, a varias situaciones reales de aprendizaje en el ámbito escolar.

PALABRAS CLAVE

educación; educación holística; emprendedurismo; desarrollo; cooperación. 


\section{INTRODUÇÃO}

A necessidade de assegurar e potenciar lógicas de desenvolvimento tem-se constituído, sobretudo desde a década de 1980, como um dos argumentos mais sólidos do imaginário económico. No entanto, tais argumentos apresentam-se, a maioria das vezes, como elementos impulsionadores e justificativos de processos de mero crescimento económico que tendem a reduzir a noção de desenvolvimento apenas a índices, comparáveis internacionalmente, de produtividade e de consumo. Essa perspetiva afigura-se-nos extremamente limitada por referência a uma noção de desenvolvimento que assegure verdadeiramente uma cidadania substantiva e não meramente formal. Com efeito, advogamos, ao longo do presente artigo, o pressuposto de que o sentido intrínseco e a finalidade do desenvolvimento global - e só dessa forma adquire o seu verdadeiro fundamento ético, social e económico - é a consecução de condições para vidas plenas e criativas, para o desenvolvimento do potencial das pessoas e para uma existência significativa, com respeito pelo ser humano, pelo ambiente, pela cultura e património histórico e pela liberdade de ser, de estar e de agir (Nussbaum, 2012).

Nesse domínio, a educação é sem dúvida uma via crucial, preparando os cidadãos para entenderem e efetivarem uma "cidadania global inteligente" (Nussbaum, 2010, p. 81), pela promoção de um ensino capacitante no que diz respeito à liberdade de pensamento crítico, de criatividade, de sentido cívico e de compreensão global de si e dos outros em um mundo partilhado e cooperativo. A educação afirma-se, desse modo, como estratégia para uma cidadania mais ativa, reflexiva e responsável, potenciando a formação de um pensamento crítico sobre o mundo, a compreensão dos papéis a cumprir e das consequências de ações e omissões, a consciência das interdependências entre as dimensões locais e globais, individuais, políticas, económicas e sociais, a compreensão empática das diferenças e complementaridades e o questionamento das desigualdades ilegítimas.

A educação é assim uma via incontornável para o acesso e fruição de direitos e práticas de cidadania. Nessa ótica, a chamada educação para a cidadania tem vindo também a ser associada progressivamente, nomeadamente em diversos documentos europeus, à formação de cidadãos proativos e empreendedores (EC, 2010; WEF, 2009). A retórica do empreendedorismo tem vindo de fato a emergir, nas últimas décadas, como salientam diversos autores (Cuervo; Ribeiro; Roig, 2007), como uma estratégia fundamental para um desenvolvimento pautado pela coesão social e económica. O estímulo a respostas inovadoras e ao envolvimento dos cidadãos na construção de alternativas sociais e económicas para os problemas individuais e/ou coletivos, identificando e explorando, de forma inteligente e sustentável, oportunidades e recursos escassos, constituem-se, sob tal perspetiva, como elementos basilares na concepção da chamada "cultura empreendedora".

$\mathrm{Na}$ verdade essa orientação tende a ser cada vez mais apresentada, em diversas abordagens político-económicas, como o paliativo miraculoso para problemas estruturais, como o desemprego ou a exclusão, sem que se reflita de forma profunda sobre os equilíbrios necessários entre o incremento das capacidades individuais e grupais para empreender e as condições e oportunidades contextuais para efetivação 
de tal intento. Sem uma reflexão de base, os riscos de transformar a retórica do empreendedorismo em estratégia de responsabilização individual para resolução de problemas supraindividuais não são displicentes. A educação tem assim de ser pensada como patamar para valorização da capacidade de iniciativa, de análise crítica e de cooperação, desenvolvendo o que chamamos de "pedagogia empreendedora" como atitude perante a vida, sem se descurar, no entanto, o investimento paralelo em políticas públicas passíveis de gerar reais oportunidades sociais e económicos.

No presente artigo procuraremos discutir, em primeiro lugar, os efeitos perversos decorrentes de uma concepção utilitarista do empreendedorismo, defendendo uma perspetiva de "pedagogia empreendedora", que traduza essencialmente a interconexão entre as diversas dimensões da existência humana. Ou seja, que estabeleça e consolide uma perspetiva de cidadania e de cooperação, que possibilite a concretização e disseminação de valores de respeito pelos contextos socioculturais e pelas pessoas, ajudando-as a criar condições (pessoais e contextuais) para a liberdade de escolha, ou, por outras palavras, para a "concretização da vida que pretendem efetivamente viver” (Nussbaum, 2010, 2012; Sen, 2003).

Centrar-nos-emos, assim, em termos de quadro teórico, no paradigma das capacidades, desenvolvido nas últimas décadas por Amartya Sen e Martha Nussbaum, entre outros, questionando, em paralelo, a lógica funcional e estrita de compreensão de competências que tem estado associada às abordagens sobre a "educação para o empreendedorismo" e, em última instância, ao paradigma dominante de crescimento económico. Um novo paradigma, associado ao desenvolvimento humano e à criação de capacidades (mais que de competências funcionais), centra-se em questões como: O que são realmente capazes de fazer e de ser as pessoas? Que oportunidades têm verdadeiramente à sua disposição para escolher a vida que pretendem e têm direito a viver? - e não fundamentalmente em questões associadas ao incremento da produtividade, à criação de negócios e ao sucesso empresarial.

Tais referenciais teóricos permitirão fundamentar uma nova perspetiva de cultura empreendedora, holística, humanista e cooperativa e de educação para a cidadania e o empreendedorismo, que procuraremos ilustrar, numa segunda parte, com o trabalho desenvolvido pelo Tree Institute - Associação para o Desenvolvimento Económico, Social e Humano (Lisboa, Portugal). Advoga-se, assim, uma pedagogia empreendedora capaz de incrementar:

a) o sentido de respeito pela dimensão global e intergrupal da existência humana;

b) a interconexão entre capacidades e oportunidades, entre saber, querer e poder;

c) a possibilidade de erro como algo de inerente a processos de aprendizagem e criatividade;

d) a necessidade de cooperar na prossecução de dinâmicas de desenvolvimento sustentáveis, logo, de criação de futuros possíveis.

Nessa ótica, uma pedagogia empreendedora pode constituir-se como um elemento estratégico fundamental na prossecução de objetivos de desenvolvimento holístico e estrutural em sociedades cada vez mais fragmentadas e aleatórias. 


\section{EMPREENDEDORISMO E CIDADANIA. QUESTÕES CRÍTICAS SOBRE CAPACITAÇÃO E EDUCAÇÃO}

$\mathrm{O}$ verdadeiro projeto educativo tem essencialmente uma finalidade antropológica e não instrumental. Istso significa que "educação, cidadania e projeto implicam-se mutuamente e devem configurar a pessoa que numa dinâmica de acção reflexiva participa na polis, de modo construtivo, crítico e prudencial" (Medeiros, 2010, p. 7).

O exercício da cidadania tem não somente uma componente formal, mas também prática e hermenêutica, ou seja, interpela o sentido da ação, pressupõe que a pessoa constitua-se plenamente como sujeito de direitos e deveres e que compreenda o seu significado, a interconexão cooperativa que pressupõe e os processos que podem conduzir à sua consolidação ou diluição.

Sob tais pressupostos, educar para a cidadania é também educar para o empreendedorismo se este traduzir essencialmente a formação ou potencialização de uma atitude pessoal e social consistente perante a vida e os contextos políticos, económicos e sociais, seja em uma dimensão de proximidade ou em uma dimensão global. Desse modo, valoriza-se em primeira instância a educação para uma atitude mais proativa, confiante e cooperativa diante das possibilidades e limitações, pessoais e contextuais, para uma perceção mais positiva sobre o selfe mais crítica e alternativa sobre as políticas e as dimensões ou prioridades essenciais do desenvolvimento.

Um empreendedor capaz de responder aos desafios do novo século, o maior dos quais a incerteza e a aleatoriedade de percursos e formas de vida, precisa de fato de compreender a integração e a interdependência entre fatores sociais e económicos, entre as dimensões locais e globais e entre elementos pessoais, familiares, grupais, comunitários e políticos, bem como a importância da cooperação em um nível micro e macro. A cooperação implica uma articulação concetual entre a ideia de capacidades centrais associadas aos direitos humanos fundamentais e a ideia de deveres. Em uma ótica mais macro, no nível interno, corresponde ao dever associado à estrutura básica da nação, responsável por distribuir uma quantidade adequada (acima dos limiares mínimos) de direitos e recursos às cidadãs e cidadãos do país, considerando que os países pobres só podem cumprir esse intento com o apoio das nações mais ricas. Do mesmo modo, as grandes empresas, as organizações e acordos internacionais, sem esquecer as populações, têm consignados determinados deveres ligados à promoção das capacidades humanas (Nussbaum, 2012).

Dessa forma, a educação para o empreendedorismo tem necessariamente de integrar, como sustentação de toda e qualquer aprendizagem, uma dimensão ética novos valores focalizados em responsabilidade social e sustentabilidade ambiental-, uma perspetiva cooperativa - incluindo o Estado, o mercado, as comunidades e as populações -, e uma visão construtivista associada à liberdade substancial (Ferreira; Albuquerque, 2013). A liberdade substancial, como iremos argumentar, só existe se ultrapassar a mera retórica e ancorar-se na existência de verdadeiras opções, o que implica que, para além de capacidades, as pessoas tenham oportunidade de as colocar em funcionamento. Como Sen (2003) afirma, por exemplo, uma pessoa que passa fome e outra que jejua têm o mesmo funcionamento no que diz respeito 
à nutrição, mas não dispõem da mesma capacidade, pois a que jejua pode escolher não o fazer, enquanto a que passa fome não tem essa escolha, o que vai condicionar profundamente muitas outras dimensões de sua vida e as possibilidades de autodesenvolvimento a diversos níveis.

A compreensão do que implica gerar oportunidades de desenvolvimento, ancoradas em uma ótica de liberdades substanciais, pressupõe, em primeiro lugar, o entendimento de que fazemos parte de um mundo heterogéneo e contraditório, o que exige a associação entre um pensamento factual de proximidade e um conhecimento complexo e dinâmico de âmbito global e enquadrador. Em segundo lugar, preconiza o desenvolvimento de políticas educativas e de inserção verdadeiramente promocionais, humanistas e prospetivas. Desse modo, advoga-se a superação de uma perspetiva meramente analítica e estática do desenvolvimento, em prol de uma visão que permita ponderar os impactos cruzados das opções e (in)ações na vida pessoal e social.

Essa visão pressupõe o entendimento (mais consistente e experiencial) dos valores e das diversas formas de ser e de interagir, bem como de questões como a eficácia, a legitimidade, a integralidade e o exercício de um poder responsável (Wenger, 2009, p. 20). A educação para a cidadania e empreendedorismo constitui-se nessa ótica como uma dimensão estratégica para um novo desenvolvimento na medida em que permita formar cidadãos reflexivos e empáticos, capazes de (re) construir cooperativamente (e não somente competitivamente) ideias e propostas em diferentes contextos e situações, produzindo desse modo um "conhecimento sociável [livable knowledge], ou seja, um conhecimento que é significativo porque possibilita novas formas de envolvimento no mundo" (idem, ibidem).

\section{EDUCAÇÃO EMPREENDEDORA E CONSTRUÇÃO DE COMPETÊNCIAS. OS LIMITES DA ABORDAGEM CENTRADA EM “HABILIDADES COMPARÁVEIS”}

O debate subjacente a uma conceção de desenvolvimento holístico e cooperativo, concebendo a pedagogia empreendedora como uma estratégia para concretização dessa finalidade, pressupõe uma análise crítica de metodologias e abordagens centradas no treino de competências funcionais. Com efeito, as competências de gestão associadas a processos formativos orientados somente para a performance e para a consecução de mais-valias económicas, em sentido estrito, não são manifestamente suficientes ou adequadas. Modelos de competências holísticas (Ferreira; Tapia, 2010) e novas estratégias pedagógicas são fundamentais para potenciar a emergência de (novos) empreendedores capazes de produzirem dinâmicas de desenvolvimento pessoal, social e económico, mais inteligentes e sustentáveis.

Uma conceção estrita de competências (centrada nas skills - habilidades), inerente a inúmeras abordagens clássicas de educação empreendedora, tem suas origens nas tradições de enfoque funcionalista e comportamental, que emergem, nos domínios da gestão, dos recursos humanos, da orientação vocacional e de carreira (Mulder, 2007; Sultana, 2009), sobretudo nas décadas de 60 e 70 do século XX.

Nesse contexto, a "cultura da performance" afirmava-se como o elemento nodal das estratégias de formação, associadas, para o efeito, a processos de mensu- 
ração e padronização de indicadores comportamentais, em detrimento de abordagens mais complexas e dinâmicas. Os objetivos focalizavam-se assim na apreciação do que os indivíduos devem ser capazes de fazer (Melton, 1994, p. 286) em virtude de descritores mais ou menos estandardizados e mensuráveis. Desse modo, a obtenção de resultados de performance satisfatórios (Jessup, 1991) constituía-se como o fator crucial para a ponderação da importância, ou irrelevância, dos esforços educativos.

Porém, ao longo da última década do século passado, o próprio conceito de competência começou a ser reequacionado e, por essa via, as orientações educativas, centradas em meras abordagens funcionalistas e estáticas, profundamente questionadas (Brown et al., 1994). As principais críticas centraram-se na impossibilidade de compreender, por meio de lógicas simplistas, atividades complexas e comportamentos, na desconsideração de valores pessoais, enquadramentos profissionais, processos grupais e influências dos contextos (Barnett, 1994; Hager; Gonczi, 1996), bem como no reducionismo inerente às tentativas de mensurar os objetivos de aprendizagem por via de resultados, desde logo condicionados por fins predeterminados, em uma espécie de "ensino mecânico para teste" (Bates, 1995).

Conceber programas educativos orientados somente por lógicas de funcionalidade económica é de fato profundamente reducionista. Desse modo, como evidencia Nussbaum (2010, p. 9), ${ }^{1}$ estamos apenas a considerar uma parcela da forma como os cidadãos se desenvolvem.

A capacidade de pensar bem sobre uma ampla gama de culturas, grupos e nações no contexto de uma compreensão da economia mundial e da história de muitas interações nacionais e de grupo é fundamental para permitir que as democracias sejam capazes de lidar de forma responsável com os problemas que enfrentamos atualmente como membros de um mundo interdependente.

Nesse sentido, as novas conceções de competência tendem a ser mais complexas e integradas (Coburn; Stein, 2006; Hager; Beckett, 1995; Lum, 1999), sob o pressuposto de que a performance pode ser influenciada, quer por atributos e condições pessoais, quer por influência de diversos condicionantes e fatores contextuais e situacionais.

Assim, as análises e orientações pedagógicas de formação de competências passam a considerar os quadros situacionais e localizados e os fatores socioeconómicos e culturais passíveis de determinar as estratégias a adoptar com diferentes grupos de sujeitos, desde logo do ponto de vista experiencial (Brown et al., 1989; Hager; Beckett, 1995). Desse modo, mais que resultados e habilidades categorizadas, é essencial, em um processo de educação empreendedora, a consideração de "mapas amplos" de competências em territórios de ensino e situações práticas (Cooper, 2008). A relação entre saber e fazer, que "pressupõe que compreensão e experiência estão em íntima conexão - e na verdade são mutuamente constitutivos" (Lave; Wenger, 1991, p. 51) -, torna-se, nessa perspetiva, um elemento crucial de

1 As traduções são de responsabilidade dos autores. 
uma pedagogia empreendedora. Um tal pressuposto, de conexão e de transição entre a compreensão e a experiência, implica necessariamente um modelo educacional complexo, assente em uma filosofia humanista e em uma conceção de conhecimento que integra, de uma forma holística e interdisciplinar, o conhecer, o ser e o fazer (Delamare-Le Deist; Winterton, 2005; Sultana, 2009).

\section{A EDUCAÇÃO EMPREENDEDORA E A CONSTRUÇÃO DE CAPACIDADES}

A alteração paradigmática que temos vindo a advogar, no âmbito da educação empreendedora como base estratégica para uma nova conceção de desenvolvimento, preconiza uma alteração da centralidade atribuída à funcionalidade e à economia, no paradigma tradicional, para uma centração na pessoa e na vida com qualidade como fins em si mesmos.

Nessa ótica, a prossecução de processos tendentes ao incremento de capacidades, no sentido de "ser capaz de [...]" (ligado às motivações, saberes, experiências) e de ter "a possibilidade de [...]" (associado a oportunidades, recursos, contextos), em detrimento de meras competências funcionais, adquire toda a relevância. Esse conceito de "capacidades", ancorado no programa filosófico-político de Amartya Sen e Martha Nussbaum, enfatiza a pluralidade e a dimensão qualitativa dos diversos fatores constitutivos da qualidade de vida das pessoas (saúde, educação, integridade física e emocional etc.), fatores estes não redutíveis a uma métrica única (como a medição do produto interno bruto - PIB), sob pena de distorções ilegítimas.

A abordagem das capacidades (capabilities) preconiza e permite de fato uma reflexão mais exigente, dinâmica e integrada relativamente a condições e problemáticas tradicionalmente compreendidas de forma espartilhada. Por exemplo, no que concerne ao problema da desvantagem socioeconómica, Sen (2003) defende a ideia de que compreender a pobreza é considerá-la algo mais que um problema de escassez de bens ou, se quisermos, de rendimento e riqueza. É sobretudo produto (e simultaneamente causa) de uma série de perdas de oportunidades que nem sempre se relacionam diretamente com o rendimento, considerado nessa ótica apenas como um meio para um fim. A resposta à pobreza não pode, pois, passar por medidas paliativas e remediativas (associadas a maioria das vezes ao aumento, via subsídios, dos rendimentos), mas exige que se tenham em consideração as falhas de capacidades e oportunidades das populações vulneráveis, nomeadamente questionando e transformando as dinâmicas atuais do mercado de trabalho, bem como outras fontes dessa concretização. As capacidades são o que Sen (2003) chama de "liberdades substanciais": um conjunto de oportunidades interrelacionadas para escolher e atuar. Desse modo, as capacidades não são simples habilidades adquiridas, mas incluem também as oportunidades criadas pela combinação entre as faculdades pessoais e o contexto político, social e económico.

Wolff e De-Shalit, na obra Disadvantage (2007), apresentam por isso argumentos contra a redução de todos os componentes da vida humana a uma escala numérica, que tende a ignorar necessariamente fatores cruciais para a compreensão e intervenção nas populações desfavorecidas. A desvantagem é irredutivelmente plural, e os seus diversos componentes variam em grande medida de forma independente entre si e a respeito do rendimento por exemplo. Desse modo, esses autores ampliam o enfoque das capacidades em dois sentidos: 
a) a necessidade de centrar a atenção não só na presença ou ausência de capacidades, mas também em sua segurança e persistência no tempo (por exemplo, não basta um trabalho, é necessário avaliar suas condições e qualidade);

b) a necessidade de analisar de que modo se agrupam as desvantagens, como uma conduz a outra e como se relacionam, por um lado e, por outro, como algumas capacidades concretas podem permitir a concretização de outras (por exemplo, a educação como fator estratégico para a participação cívica e política).

A liberdade de escolha é, nessa medida, a base para o desenvolvimento, conduzindo a um conjunto de oportunidades ou liberdades substanciais para as populações. É, pois, um enfoque comprometido com as faculdades de autodeterminação das pessoas e pluralista em valores.

Nussbaum (2012) refere-se também às "liberdades substanciais" como "capacidades combinadas" (o conjunto de oportunidades para escolher e atuar na situação política, económica e social concreta). Ou seja, a consideração de impactes pelo e no contexto de vida. Nesse sentido, as capacidades pessoais, as características de uma pessoa (traços de personalidade, intelecto, emoções, estado de saúde, autoconcepção, aprendizagens anteriores, entre outros aspetos) são muito relevantes, mas apenas uma parte das "capacidades combinadas".

Desse modo, um dos aspetos mais importantes das sociedades que pretendam construir um desenvolvimento substancial é o apoio ao desenvolvimento das capacidades internas, por meio da educação, dos recursos necessários para desenvolver a saúde física e emocional, do apoio familiar, entre outras. É, pois, particularmente importante promover políticas públicas e intervenções verdadeiramente substantivas, evidenciando, por um lado, a enorme importância estratégica de uma educação para o empreendedorismo que assuma um cariz holístico, cooperativo e contextualizado e, por outro, a necessidade de articular um trabalho de capacitação, com os sujeitos, e com intervenções, políticas, sociais e económicas, de capacitação contextual, promovendo estruturas de oportunidade substanciais, e não somente normativas e formais.

A capacidade é assim apenas uma das faces da moeda, a outra é o funcionamento, ou seja, a realização concreta, ativa, de uma ou mais capacidades. Note-se que realização ativa não se confunde com estratégias de ativação presentes em inúmeras políticas públicas europeias da atualidade, sobretudo no domínio do emprego. Capacidade significa, como explicitado, "oportunidade de selecionar", liberdade para escolher. Nesse sentido, promover capacidades é promover áreas de liberdade. Isso não é sinónimo de condicionar o funcionamento das pessoas em determinado sentido. $\mathrm{O}$ enfoque das capacidades afasta-se assim de toda a tradição económica que mede o valor de um conjunto de opções em razão do melhor uso e do melhor proveito que se possa retirar delas. A liberdade de optar tem, nessa perspetiva, um valor intrínseco e não utilitarista.

Por tais pressupostos, a educação é um elemento central, já que permite potenciar as aptidões já existentes nas pessoas, aceder a outras e transformá-las em capacidades internas experienciáveis e multiplicáveis. É, pois, um recurso e um processo de grande importância para afrontar os problemas de desvantagem e de 
desigualdade, ${ }^{2}$ pelo que a ponderação do que significa educar e, sobretudo, como, sob pressupostos de cidadania, ética e humanismo; é um elemento estratégico central na definição de novos paradigmas de desenvolvimento, por exemplo apostando no desenvolvimento e na consolidação de aptidões ligadas ao pensamento crítico, à empatia, à compreensão histórica, ao entendimento do sistema económico e político global, como elementos essenciais para o exercício de uma cidadania democrática e responsável.

\section{APONTAMENTOS DE EXPERIÊNCIAS E APRENDIZAGENS PELA UTILIZAÇÃO DO MODELO EM ÁRVORE (TREE MODEL)}

Como temos vindo a advogar, a educação para o empreendedorismo, associada a um programa de educação para a cidadania e cooperação, constitui-se como um referencial para um processo de desenvolvimento pessoal e social de cariz integral e estratégico. $\mathrm{O}$ trabalho desenvolvido no Tree Institute (Lisboa, Portugal) radica nos pressupostos básicos de uma educação para o empreendedorismo, holística (considerando os sujeitos, os contextos e respetivas conexões), humanista (colocando, em primeiro lugar, a construção, com os sujeitos, de capacidades para um posicionamento crítico e motivacional perante a si próprios e à vida), cooperativa (valorizando a interaprendizagem, a capacidade de observar criticamente a realidade e os recursos, a conexão com os territórios e o pensamento crítico global) e ancorada na cidadania (estimulando projetos concretos capazes de produzir impactos, quer na capacidade de ação e autoestima dos sujeitos, quer nas condições de vida própria ou de terceiros).

\section{FATORES CRÍTICOS DE ESTRUTURAÇÃO E APLICABILIDADE DO MODELO EM ÁRVORE}

O Tree Model - Modelo em Árvore (Ferreira, 2011) - constitui-se como um modelo holístico aberto de educação para o empreendedorismo de base cooperativa, relacionando a pessoa, suas motivações, suas habilidades para empreender e o seu meio ambiente (escola, grupos, trabalho, comunidade). O modelo é concebido figurativamente como uma árvore. A raiz é a base na qual são promovidos os

2 A reflexão, que ultrapassa os limites e objetivos do presente artigo, sobre a igualdade de oportunidades e de resultados no acesso e frequência à escola é, a esse nível, essencial e está na base do que se pode considerar capacitação e funcionamento, por referência aos contextos sociais e económicos. Para maiores informações a esse respeito, ver James Coleman, $\mathrm{O}$ conceito de igualdade de oportunidades educacionais, Educação, Sociedade e Culturas, n. 34, 2011, p. 137-155; Carlos Alberto Vilar Estêvão, Justiça complexa e educação. Uma reflexão sobre a dialectologia da justiça em educação, Revista Crítica de Ciências Sociais, n. 64, 2002, p. 107-134; Sharon Gewirtz. Conceptualizing social justice in education: mapping the territory, Journal of Education Policy, n. 13, v. 4, 1998, p. 469-484; Stephen J. McNamee e Robert Miller, Jr. The meritocracy myth. Rowman \& Littlefield, 2004. 
comportamentos e as competências básicas. $\mathrm{O}$ tronco corresponde às estratégias de desenvolvimento de competências, assegurado por processos de ação e experienciais em projetos que agregam motivações pessoais, interesses e/ou necessidades. Os ramos correspondem à orientação desses projetos para realizações concretas e mobilização ativa das competências. Finalmente, os frutos são os resultados ou produtos dos projetos.

As competências-chave na "raiz" do modelo correspondem a competências comportamentais e competências de desempenho. As competências comportamentais devem ser observáveis e cross-transferíveis, ou seja, são competências abertas (as chamadas soft skills) e não associadas a uma tarefa ou função específicas. São elas a autoconfiança, a capacidade de iniciativa e a resiliência. A autoconfiança e a resiliência são os pilares básicos para se ser capaz de mover-se de um estado de inércia para um estado de ação. Saliente-se, porém, que essas três competências não indicam a direção ou a qualidade das ações delas decorrentes. $\mathrm{O}$ ato empreendedor e a criação de valor que thes estão associados encontram-se sempre em relação com o ponto de partida e o contexto pessoal. Como Wenger (2009, p. 25) afirmou: "Como cidadãos aprendentes, provimos de quem somos - nossas histórias pessoais, conexões, redes, visão, aspirações e posição na topografia da prática - para encontrar formas de participação que aumentem a capacidade de aprendizagem".

Outro tipo de competências comportamentais, no cruzamento com competências de desempenho, está associado com a capacidade de organização, relações de cooperação e inovação. A inovação introduz o grau potencial de utilidade da iniciativa associada à criação de valor. $\mathrm{O}$ desenvolvimento da capacidade de criar novas abordagens para os problemas e contextos requer uma orientação pessoal (intimamente ligada à autoconfiança e resiliência), capaz de romper com as convenções e procedimentos estabelecidos, bem como um forte foco e persistência para materializar ideias inovadoras. As competências de organização (no sentido de ser capaz de capturar e alinhar recursos externos de natureza diferente) e as competências de relacionamento cooperativo imputam à iniciativa, inovadora ou não, estrutura e dimensão.

Para o desenvolvimento de competências de desempenho, as estratégias de ensino do empreendedorismo devem mobilizar os conhecimentos e o know-how do universo da pessoa. Particularmente importante nessa perspetiva é a concepção do (bom) erro e do fracasso. Especialmente em tarefas novas e complexas, a questão não é se irão existir erros ou não, mas a forma de lidar com eles. Em um processo de aprender-fazendo, deve ser assegurada uma abordagem ecológica integrando tanto as experiências positivas quanto as negativas como recursos de aprendizagem e avanço. Desse ponto de vista não há verdadeiramente erros ou falhas, mas essencialmente oportunidades de aprendizagem (Lindsey, 1990).

O "tronco" do modelo corresponde ao desenvolvimento de um projeto ancorado nos fundamentos pedagógicos das metodologias de aprender-fazendo.

Os "ramos", por seu turno, estão relacionados com a natureza das atividades. Nesse modelo, as atividades devem ser reais, e não simulações, e estar intimamente ligadas aos interesses das pessoas, aos valores, aos contextos de vida (escola, trabalho, negócios, comunidade) e às motivações. 
Os "frutos" correspondem aos resultados tangíveis. Essa é uma das características distintivas do Modelo em Árvore e um fator crítico de sucesso. Em termos concretos, é possível identificar e avaliar (Ferreira; Tapia, 2010) dois níveis de resultados em relação dinâmica: resultados de aprendizagem e resultados de desempenho. Os resultados de desempenho, nomeadamente, estão relacionados com o nível de cumprimento dos objetivos do projeto. Considerando-se a produção de resultados reais importante (mesmo que seja apenas em uma escala muito pequena), está instalada uma relação direta entre uma ideia, um esforço ou uma ação e um resultado. Por outras palavras, essa relação consubstancia a ideia de "participação no mundo" e coloca as pessoas em contacto consciente com a realidade.

A nossa proposta de trabalho (Ferreira; Albuquerque, 2013), no âmbito de uma pedagogia empreendedora, é, em suma, baseada em uma lógica de "mínimo método comum", o qual consiste na identificação e aproveitamento dos fatores críticos para uma educação holística empreendedora. Nessa perspetiva, consideramos sucessivamente a dimensão da pessoa e respetivas motivações, do grupo e do contexto (de proximidade e global). Essas dimensões devem ser encaradas como um único processo e não podem ser dissociadas.

$\mathrm{Na}$ verdade, quando posicionamos a questão do empreendedorismo como produto de competências integrais, ou seja, não baseada essencialmente em conhecimentos de gestão, mas em "capacidades" e "funcionamentos" (Sen, 2003), o paradigma da educação para o empreendedorismo muda radicalmente. Na medida em que procuramos obter novos resultados, formulamos também novos objetivos e, por essa via, somos conduzidos à necessidade de desenvolvimento de novos modelos pedagógicos desde idades precoces (Heckman, 2011).

Nesse sentido, podemos identificar como fatores críticos que devem figurar em um processo holístico de educação empreendedora três pressupostos: o desenvolvimento de motivações intrínsecas; a aprendizagem da cooperação e a tangibilidade dos projetos e respetivos resultados.

\section{A) Motivações e interesses pessoais (intrínsecos)}

Se queremos que o empreendedor seja um ator social, este deve ter um forte sentido de autodeterminação, a percepção de que pode desenvolver os seus interesses e orientações, em um espaço, simultâneo, de liberdade individual e de responsabilidade coletiva, ou seja, em oposição a uma atitude de espectador social e de delegação. Em uma ótica de educação para o empreendedorismo, as motivações intrínsecas têm um duplo papel: de realização pessoal e de suporte de ação consistente. As motivações intrínsecas caracterizam-se por ser um fim em si mesmas, não dependendo de uma recompensa exterior. Relacionam-se, pois, com um sentimento de autonomia e procuram satisfazer algum tipo de necessidade pessoal. Assim, a pessoa mobiliza um conjunto de recursos, estratégias e afetos, de maneira autónoma, para realizar a tarefa que pode ser gratificante por si. A motivação está diretamente relacionada com o desempenho, e vice-versa, e encontra-se, como tal, na base do comportamento empreendedor já que se associa à persistência, direção da ação e intensidade/energia do esforço, em uma ótica de active striving, como refere Nussbaum (2012). 
Um dos problemas recorrentes, enunciado por professores e animadores no desenvolvimento de projetos empreendedores no contexto escolar, é a falta de motivação, traduzida pela baixa atividade e persistência dos alunos na prossecução de ações. A avaliação efetuada no decurso dos processos formativos que tivemos oportunidade de desenvolver nas escolas ao longo da última década ${ }^{3}$ revelou, porém, dois aspetos centrais: por um lado, o fato de os projetos escolares serem propostos e/ou condicionados pelos professores, suscitando um tipo de adesão superficial por parte dos alunos (o que é típico de ambientes educativos muito estruturados e dirigidos), por outro lado, o uso de estratégias pedagógicas tradicionais, que condicionam a efetivação de processos mais criativos e experienciais em sala de aula.

A título de exemplo, podemos referir que em uma turma do $12^{\circ}$ ano do ensino profissional ${ }^{4}$ envolvida em um projeto empreendedor em contexto escolar, a professora declarou que os alunos "não queriam fazer nada e que desistiam facilmente". Quando visitámos a turma, questionámos o grupo sobre suas ideias de projeto e sobre todo o processo desenvolvido até ao momento para tentarmos compreender a razão da desmotivação do grupo. Os jovens disseram-nos: "apresentámos o projeto $\mathrm{X}$ e a professora não gostou. Apresentámos a ideia $\mathrm{Y}$ e também não gostou. Agora estamos a fazer o projeto sugerido pela professora". Ou seja, a docente transformou o projeto empreendedor em uma tarefa escolar de rotina, sendo, pois, a vontade de agradar à professora o único elemento motivacional dos alunos.

Nessa perspetiva, considera-se que, para além da conquista de autonomia, uma pessoa motivada implica-se em tarefas mais desafiantes, isto é, que estejam acima de suas capacidades e expetativas usuais, dispondo-se a correr mais riscos, a fazer novas experiências e a assumir novos comportamentos para superar os desafios. A compensação para produzir um projeto de intervenção deve também estar associada aos resultados do próprio projeto e não a uma recompensa externa (que se pode traduzir em um prémio, no desejo de agradar ao professor/adulto ou na atribuição de uma classificação escolar). Em uma experiência realizada por Groves, Sawyers e Moran (apud Katz; Khan, 1989), em 1987, com crianças em idades pré-escolares, relativa à fluência (um dos indicadores de criatividade) demonstrou-se que as crianças integradas em grupos com uma recompensa externa associada obtinham resultados inferiores em comparação com crianças integradas em grupos sem recompensas externas associadas.

Com efeito, em nossa experiência em educação empreendedora temos vindo a confirmar a mesma conclusão. Por exemplo, um grupo de uma turma do $2^{\circ}$ ano do ensino básico (crianças com 7-8 anos) foi desafiado a desenvolver, em 2010, um projeto próprio e foi identificado um problema relacionado com a disposição do mobiliário do seu refeitório. Incentivados a resolver a situação, os alunos desenharam

3 Referir-se-á, no próximo ponto, sobretudo ao trabalho no âmbito do Programa Nacional de Educação para o Empreendedorismo em mais de cem escolas/agrupamentos e aplicado, posteriormente, em escolas da Casa Pia e Santa Casa da Misericórdia de Lisboa (internatos de jovens em situação de vulnerabilidade).

4 Casa Pia (internato para jovens vulneráveis, Lisboa), 2010, curso profissional, grupo de sete alunos entre 16 e 18 anos. 
um novo layout do refeitório, reuniram (sozinhos) com os órgãos de gestão da escola e, depois, com o responsável do refeitório, explicando, de forma autónoma, o seu ponto de vista. Por fim, o grupo viu a sua ideia aceite e aprovada e foi autorizado a concretizá-la. O papel da professora foi somente incentivá-los a realizar a proposta, orientá-los para as pessoas com quem deveriam falar e acompanhá-los até aos locais de reunião, nunca intervindo na ideia em si, nem na forma de a apresentar. A gestão da escola (o gestor e o responsável) foi envolvida nessa experiência, viabilizando a solução, mas, em simultâneo, criando obstáculos passíveis de serem ultrapassados pelo grupo. Em suma, as motivações intrínsecas permitem encarar tarefas desafiantes, com elevada autonomia e desempenhos superiores, se forem concretizadas em num ambiente promotor desse mesmo exercício.

Nessa perspetiva, compete aos animadores/professores criarem um ambiente estruturado para a motivação que consiste em:

a) promover um ambiente de estabilidade e confiança no qual é permitido errar e experimentar sem críticas e penalizações;

b) proporcionar meios básicos (emocionais, sociais e físicos) e adequados ao desenvolvimento de projetos;

c) viabilizar o cumprimento de tarefas e a superação de objetivos desafiantes, que sejam compatíveis com o escalão etário e o nível conhecimento dos participantes.

\section{B) Trabalho em grupo: a lógica da cooperação e intercompreensão}

O segundo fator crítico para uma educação holística para o empreendedorismo é a aprendizagem do trabalho em grupo. A obrigatoriedade de desenvolver projetos grupais é intencional e tem por finalidade colocar a pessoa em um conjunto de relações interpessoais e de tensões de grupo. Nesse contexto, ainda que cada aluno possa partir de ideias próprias, precisa de aprender a enquadrá-las com outras ideias, ouvir novas opiniões e procurar enriquecer um projeto mais lato.

Os professores têm um papel muito importante no impulso que podem dar a essa aprendizagem cooperativa e na integração ecológica das várias ideias e personalidades. A questão do trabalho individual versus cooperação é um tema crucial na atualidade, já que no geral o "herói empreendedor" é apresentado como um indivíduo, independente, líder, que procura oportunidades de negócio e maximizar o capital, o que, como foi dito, pode produzir inúmeros efeitos perversos. Assim, a questão do trabalho cooperativo, em grupo, adquire uma dimensão estratégica e crítica na educação para a cidadania e o empreendedorismo.

$\mathrm{Na}$ metodologia de projeto na sala de aula, inerente ao modelo Tree Model (Ferreira, 2011), as pessoas definem as suas próprias ideias de ação/iniciativa para depois as exporem ao grupo e procurarem agrupar-se livremente por algum tipo de interesse ou afinidade. Como só são admitidos grupos, os participantes têm de procurar outros parceiros com projetos e/ou objetivos semelhantes e depois integrá-los num só, em torno de objetivos comuns. Esse trabalho de afiliação livre permite aprendizagens e experiências significativas, tanto do ponto vista cognitivo 
(raciocinar sobre suas ideias e as dos outros, procurando relacioná-las de forma aberta e não estruturada a priori), como emocional, lidando com seus sentimentos e os dos outros pelo desenvolvimento de relações empáticas.

$\mathrm{Na}$ abordagem do Tree Model, optou-se por criar um referencial de seis competências comportamentais-chave e respetivos indicadores de avaliação, ${ }^{5}$ no qual se incluíram as relações interpessoais cooperativas (Quadro 1) definidas da seguinte forma:

1. estabelece relações com os outros, desenvolvendo e promovendo redes sociais em torno de propósitos comuns;

2. coopera com os outros para atingir os seus próprios objetivos e os do grupo;

3. colabora com os outros no trabalho e na procura de soluções que possam ser positivas para todas as partes envolvidas.

\section{Quadro 1-Referencial de competências comportamentais de relacionamento cooperativo e respetivos indicadores de avaliação}

\begin{tabular}{|l|l|l|}
\hline Competência-Chave & \multicolumn{1}{|c|}{ Definição Operacional } & \multicolumn{1}{c|}{ Ações Potenciadoras } \\
\hline $\begin{array}{l}\text { Relacionamento } \\
\text { Cooperativo }\end{array}$ & $\begin{array}{l}\text { Estabelecer e desenvolver contactos } \\
\text { interpessoais que promovem uma } \\
\text { rede de relacionamentos que possam } \\
\text { conduzir à identificação de situações } \\
\text { ou soluções que possam ser benéficas } \\
\text { para todas as partes envolvidas. }\end{array}$ & $\begin{array}{l}\text { Proporcionar atividades em que seja } \\
\text { necessário colaborar e/ou pedir ajuda } \\
\text { a outros para atingir os objetivos } \\
\text { individuais. Proporcionar atividades de } \\
\text { equipa em que o resultado que conta é } \\
\text { o do conjunto e não o de cada membro } \\
\text { do grupo. }\end{array}$ \\
\hline Indicadores de Avaliação: \\
- Utilizo a rede de relações interpessoais para conseguir apoio para ideias/projetos e \\
atingir os meus objetivos; \\
- Apoio e atuo de acordo com a decisão final do grupo, mesmo quando essa decisão não \\
reflete a minha própria opinião; \\
- Atuo para melhorar o relacionamento com pessoas-chave, de forma que possa \\
conseguir a cooperação necessária à resolução de problemas e ao cumprimento de objetivos; \\
- Solicito a contribuição dos colegas para o cumprimento de objetivos; \\
- Expresso a minha opinião sem desrespeitar a opinião dos outros; \\
- Partilho informação e conhecimento com os outros para permitir o cumprimento \\
dos objetivos do grupo; \\
- Atuo de modo que possa privilegiar os resultados da equipa, em vez de procurar crédito pessoal; \\
- Aceito corresponsabilidade e atuo cooperativamente para atingir os resultados partilhados; \\
- Demonstro interesse em ajudar os outros a resolverem problemas e a cumprir objetivos; \\
- Utilizo um elevado grau de diplomacia e tacto quando interajo com os outros.
\end{tabular}

Fonte: Ferreira e Tapia (2010, p. 41ss).

5 As competências-chave identificadas são: autoconfiança, iniciativa, organização, resiliência, inovação e relacionamento cooperativo (ver referencial completo e indicadores de avaliação em: <http://www.tree-institute.org/publica/ref\%20formacao\%20compet $\% 20$ empreend\%20IEFP.pdf>). 


\section{C) O Contexto: Intervenção real}

O terceiro fator crítico para o desenvolvimento de uma educação empreendedora é a concretização e a tangibilidade dos projetos em sala de aula. Nesse âmbito, defendemos que, considerando o nível etário dos alunos (o que implica a utilização de metodologias diferenciadas), estes podem intervir em sua própria vida ou na dos outros, procurando acrescentar algum tipo de melhoramento, contributo ou solução. Esse trabalho real é fundamental para a educação para a cidadania ativa e para a democracia, com impactos no desenvolvimento da inteligência prática dos sujeitos e na capacidade de pensamento crítico sobre a sua própria vida, expetativas e contextos. Essa abordagem de projeto real, em oposição aos projetos estritamente virtuais, muito vulgarizados, baseados em estudos ou simulações, pretende ligar a pessoa/ grupo à sua realidade, bem como incentivá-los a aprender a intervir civicamente.

Já há mais de um século, John Dewey (1897, artigo 3, parágrafos 2-3) salientava a esse propósito que: "A educação [...] é um processo vivencial e não uma preparação para a vida futura. [...] a escola deve representar a vida presente - a vida tão real e vital para a criança como a que ela vive em casa, no bairro ou no pátio".

Ou seja, a escola e o projeto devem ser parte integrante do contexto em que a pessoa se insere e, por isso, é passível de ser criticamente analisado, melhorado ou alterado pela ação intencional do grupo e de cada um dos seus elementos.

$\mathrm{O}$ paradigma contextual está subjacente à metodologia Tree Model. O tipo e níveis de impactes das ações e projetos pedagógicos empreendedores podem ser definidos da seguinte maneira:

Quadro 2-Tipo e níveis de impacte de projetos empreendedores: indicadores de avaliação

\begin{tabular}{|l|l|}
\hline Níveis de impacte da ação & \multicolumn{1}{|c|}{ Descrição } \\
\hline Informação & $\begin{array}{l}\text { O formando obteve mais informação e conhecimentos, } \\
\text { manifestado em relatórios ou trabalhos de caráter académico. }\end{array}$ \\
\hline Sensibilização & $\begin{array}{l}\text { O formando promoveu açães públicas de intervenção no meio, } \\
\text { manifestado em ações de divulgação, sensibilização e reflexão. }\end{array}$ \\
\hline Esforços reais & $\begin{array}{l}\text { O formando interveio na "realidade" procurando a } \\
\text { sua alteração, manifestado, por exemplo, em recolha, } \\
\text { ou construção, de meios de intervenção. }\end{array}$ \\
\hline Resultados reais e tangíveis & $\begin{array}{l}\text { Idêntica à anterior, mas centrada nos resultados, como: produziu } \\
\text { o primeiro emprego, acompanhou idosos durante x tempo etc. }\end{array}$ \\
\hline
\end{tabular}

Fonte: Ferreira e Tapia (2010, p. 67).

Essa escala deve ser compreendida de forma inclusiva, ou seja, nenhum dos níveis de impacto deve ser equacionado de forma isolada dos outros. Se é verdade que a motivação tem impacto nos resultados que as pessoas obtêm, também é verdade o inverso, ou seja, a visualização de resultados é um feedback essencial para elevar ou manter o grau de motivação. Segundo Kearney (2009), quando a construção do conhecimento acontece durante a interação com o meio ambiente, a aprendizagem e, consequentemente, os comportamentos podem ser modificados de forma mais eficaz, constituindo assim um mediador natural entre a pessoa, o grupo e a sociedade. 


\section{AVALIAÇÃO E APRENDIZAGENS DECORRENTES DA APLICAÇÃO DO MODELO EM ÁRVORE}

O Modelo em Árvore, cujos pressupostos brevemente explicitámos, tem sido aplicado em diversos contextos formativos, quer no âmbito do ensino profissional e destinado a adultos, quer no quadro da escolaridade obrigatória. Nesse âmbito, destacam-se a adoção e a aplicação do modelo pelo Ministério da Educação português no Projeto Nacional de Educação para o Empreendedorismo (PNEE), entre $2006 / 2007^{6}$ e 2009/2010, em noventa e nove escolas, localizadas em todo o território nacional.

No final da primeira fase de implementação do PNEE, o projeto e o modelo pedagógico que lhe serviu de suporte (Tree Model) foram sujeitos a avaliação por uma entidade externa independente (Correia, 2010, 2011), permitindo recolher evidências empíricas e fundamentar um conjunto de aprendizagens e de dimensões operativas passíveis de criar condições para a aplicação efetiva do modelo em contexto escolar e para a consequente concretização dos resultados pretendidos.

O estudo avaliativo em epígrafe decorreu em duas fases. A primeira (2010) consistiu no levantamento, por via de inquérito online, de processos, práticas e resultados das escolas participantes no PNEE. Responderam ao inquérito 44\% do total de escolas, isto é, 228 escolas (3.425 alunos participantes; 127 projetos). $\mathrm{Na}$ segunda fase (Correia, 2011) foram realizados oito estudos de caso, centrados nos projetos $^{7}$ identificados na primeira fase, de modo que pudesse perspetivar quais as condições e práticas potenciadoras de sucesso na implementação do modelo educativo empreendedor, ou quais, em contraponto, os fatores ou circunstâncias de bloqueio. Assim, são de destacar as seguintes conclusões:

a) em todos os casos os responsáveis pelas escolas consideraram a pedagogia empreendedora e o projeto como elementos muito relevantes na "aproximação dos alunos à escola, bem como um dos mais adequados e eficazes meios de aproximação dos diferentes agentes/grupos envolvidos na escola (alunos, professores, pessoal, pais e instituições externas)" (Correia, 2011, p. 6). O incremento motivacional verificado, sobretudo nos alunos, consubstanciou, na ótica dos entrevistados, de forma unânime, um impacto muito positivo para toda a comunidade educativa, com consequências diretas "na relação estabelecida com a escola, no maior índice de satisfação e um menor índice de abandono escolar [...]. Vários professores nos transmitiram a surpresa de terem visto seus alunos empenhados em permanecer dentro da escola para além do horário estabelecido para, de forma voluntá-

6 O ano letivo 2006/2007 correspondeu à implementação do projeto-piloto (em vinte e três escolas participantes).

7 Do grupo de oito escolas selecionadas, constam: a) escolas bem-sucedidas na implementação de projetos de educação para o empreendedorismo; b) escolas que implementaram e desistiram; c) escolas que nunca foram capazes de implementar e d) escolas que sentiram dificuldades em implementar (Correia, 2011). 
ria e por sua decisão, trabalharem nos respetivos projetos" (idem, ibidem). A dimensão de projeto tangível inerente ao Tree Model parece ser, pois, um fator muito relevante em termos motivacionais e na criação de conexões efetivas entre os alunos, a escola e os restantes elementos da comunidade educativa;

b) também no domínio das mudanças comportamentais, os resultados foram unânimes: a pedagogia empreendedora foi considerada essencial na construção de um "ambiente escolar mais participativo, disciplinado e responsável" e no desenvolvimento de capacidades, atitudes e valores relacionados com a iniciativa e a responsabilidade (idem, p. 7).

Da avaliação efetuada, várias aprendizagens podem ser retiradas, quer do ponto de vista estrutural, quer do ponto de vista substancial. Em termos substanciais, são de sublinhar os seguintes aspetos, basilares na filosofia do Modelo em Árvore:

a) a importância da autonomização dos alunos e da possibilidade de apresentação, valorização e concretização de suas próprias propostas;

b) a tangibilidade dos projetos desenvolvidos transformando-os em ações consequentes e não em meros exercícios pedagógicos de avaliação de desempenho;

c) a integração do "ensaio e erro" como estratégia fundamental de aprendizagem na busca de novas soluções, e

d) a exigência do trabalho em grupo como aprendizagem de negociação ética, de valorização da diferença e de construção de opções criativas e cooperativas.

Em termos estruturais, a avaliação permitiu também identificar alguns fatores de relevo, potenciadores ou constrangedores, dos objetivos e dos resultados a atingir com o modelo. Destacam-se três, que se afiguram como os mais significativos para a reflexão em curso:

a) o fator tempo - os projetos necessitam de tempo de desenvolvimento e de consolidação e avaliação pelo que não se adequam a períodos temporais curtos (por exemplo, um ano letivo), exigindo um plano de ação global por parte da escola que identifique os resultados a atingir numa ótica prospetiva. Esse aspeto é não só importante como plano estratégico de aprendizagem, mas também elemento motivacional e de persistência da tarefa para os estudantes e responsáveis envolvidos. Em contrapartida, esse desiderato exige o enquadramento do projeto no conjunto das disciplinas lecionadas, bem como alguma permanência do corpo docente e a diminuição do tempo dedicado a tarefas burocráticas (muito enfatizado, na avaliação, como fator constrangedor de maior implicação), aspetos que implicam igualmente decisões políticas estruturais (nomeadamente na flexibilização dos programas curriculares, extensos e espartilhados);

b) o fator contexto - não apenas o contexto proximal (escola), que pode potenciar ou constranger as dinâmicas de autonomia, iniciativa e tempo dos estudantes e professores (pelo tipo de dirigentes, objetivos a cumprir pela 
escola, por exemplo em rankings nacionais, número e motivação de professores, entre outros aspetos), mas também o contexto envolvente que pode dificultar ou inviabilizar a aplicação dos projetos idealizados. Nesse sentido, o levantamento de necessidades da comunidade e a superação das barreiras da escola com o contexto são fundamentais, quer numa perspetiva de abertura da escola à comunidade de que faz parte, e vice-versa, quer numa ótica de cidadania cívica e social dos alunos e demais participantes nos projetos. Já salientámos como essa dimensão da vida real e do conhecimento experienciável é importante nos fundamentos do Modelo em Árvore;

c) o fator pedagógico - o professor, como orientador e mediador, é crucial na construção de valores e de um percurso formativo consistente. Considerando que uma escola empreendedora não é apenas um local de transmissão de informações, mas de construção de sabedoria, é importante o incentivo ao pensamento crítico e a capacidade motivacional que permita despertar o gosto pela aprendizagem e sua consolidação em âncoras consequentes. $\mathrm{O}$ professor é um elemento essencial nessa equação, adotando uma pedagogia ativa e de construção conjunta da aprendizagem, e não uma pedagogia passiva de mera transmissão de dados e informações sem conexão com o mundo real.

\section{CONSIDERAÇÕES FINAIS}

A educação para o empreendedorismo pode de fato constituir-se como uma orientação estratégica de enorme relevância na prossecução de um desenvolvimento integrado, eticamente fundamentado e essencialmente promotor da liberdade de escolha efetiva dos cidadãos. Para o efeito é, porém, necessário, como procurámos argumentar ao longo do artigo, a adoção de estratégias políticas e educativas que não esqueçam a dimensão local, global e supraindividual das problemáticas atuais e que, ao mesmo tempo, preconizem processos pedagógicos capazes de incrementar a dimensão de cidadania, de pensamento crítico e holístico, de cooperação e de compreensão do papel relativo de cada um e de todos na construção de projetos empreendedores e de desenvolvimento, que tenham efetivos impactos na vida concreta dos cidadãos e das comunidades locais.

O empreendedorismo, como atitude perante a vida, corresponde, como procurámos advogar, a um conjunto de valores e de comportamentos acessíveis a qualquer pessoa, em qualquer contexto e independentemente de sua origem, qualificação ou recursos (Ferreira; Tapia, 2011). Ainda assim, o contexto (proximal, nesse caso, a escola, e experiencial) exerce forte influência, seja na abertura à aquisição de novos valores e atitudes, seja, sobretudo, na aplicação consequente de novas aprendizagens e de processos de mudança. Uma mudança que, como argumentámos, só é verdadeiramente consistente e promotora de desenvolvimento como liberdade (Sen, 2003) se for cooperativa e holística.

Nesse sentido, a reflexão de base é de que modo a escola contribui para a construção da ideia de ser pessoa, ou seja, qual o seu papel na edificação da capacidade de escolhas eticamente fundamentadas, cooperativas, autónomas e em liberdade. Por 
outras palavras, como impulsiona cada indivíduo a ser sujeito, pela afirmação de si com o outro, considerando que só há verdadeira liberdade se se cultivar o pensamento crítico, o pensamento criativo e o pensamento implicado.

A "mcdonaldização" da escola (conceito desenvolvido por Ritzer, em 1996, para referir-se ao excesso de racionalização dos postos de trabalho), como alguns autores já referem, pode conduzir, na verdade, à diluição da compreensão do papel do homem no mundo e da responsabilidade partilhada na resposta às grandes questões que afetam a humanidade. Como afirma Gadotti (2004, p. 229), "esse é um dos atrasos da nossa civilização. Avançamos muito no plano das tecnologias e pouco no que se refere ao governo do humano". A educação para a cidadania e para a cooperação, que o Modelo em Árvore procura concretizar, é, pois, essencial para a manutenção de valores centrais para os fundamentos da humanidade e do futuro.

A preocupação com as finalidades do ato educativo, no mundo plural e imprevisível em que nos encontramos, está patente em diversos fóruns internacionais, como na Comissão Internacional sobre Educação para o século XXI, além de ter sido largamente explorada no Relatório Jacques Delors (2010), Educação, um tesouro a descobrir. A reflexão teleológica sobre a escola (tal como a questão subjacente dos meios a utilizar) é, no entanto, extremamente complexa e com respostas muito diferenciadas, o que denota claramente o foco político que enquadra (no sentido mais essencial de definição coletiva e deliberativa da polis) - Será que transmitir conteúdos é o grande papel da escola? O que é preciso saber? Ou melhor, o que é essencial saber e com que fins? O que é que o professor pode ensinar que os alunos não possam encontrar na internet, numa espécie de conhecimento em tempo real? "O que é que a escola precisa de aprender antes de ensinar"(Mosé, 2013)? Na verdade, uma reflexão sobre os fins enfatiza, desde logo, as perspetivas de que a educação e a escola devem ser preocupação de toda a comunidade, e não de esferas dissociadas.

Ora, tendo por base essa ideia da escola como instância de formação humana e de cidadania, é essencial considerar brevemente aqueles que podem ser os paradoxos-base da escola atual:

Primo, a perda da noção do todo: aprender não pode ser sinónimo de isolar e espartilhar - Onde é que o conhecimento se encontra com a vida? Como pensar o todo numa escola/educação fragmentada? A grande questão da compreensão do mundo e da humanidade radica nesse ponto. $\mathrm{O}$ pensamento fragmentado (consubstanciado, por exemplo, no ensino por disciplinas separadas) afasta o ser humano da vida; a escola devia ensinar a aprender, reaprender a ver, ouvir, pensar, preparar para a atuação política na sociedade, como refere Morin (2001). Para tal, o professor precisa de estimular a curiosidade e a aprendizagem, aprender a integrar "o erro" no processo de aprendizagem. A mera acumulação de conteúdos e de um pensamento estratégico e funcional neutraliza a capacidade de reflexão holística.

Secundo, a defesa da ideia de que a escola não é um lugar de afetividade (Mosé, 2013): etimologicamente, o termo afeto deriva do latim afficere, afectum, ou seja, produzir impressão, ser "afetado por", não ficar indiferente; comover o espírito e, por extensão, unir, fixar. A escola tem de ser um lugar 
onde o sujeito se fixa, se liga. Ninguém aprende verdadeiramente o que não percebe, o que não "afeta", o que não adquire sentido para si. Como diz Rubem Alves (1994): "a semente do pensamento é o sonho, por isso os educadores antes de serem especialistas em ferramentas do saber deveriam ser especialistas em amor, intérpretes dos sonhos". Daí a importância de, na escola, criar as raízes para uma reflexão ética, sobre si mesmo, sobre a ação e sobre o outro, promover o cuidado, o sentido ético, a prudencialidade, a sensibilidade estética e a compaixão como virtudes; compaixão entendida como o sentimento básico a ser cultivado no/pelo aluno na medida em que conhece o mundo com as desigualdades criadas pelos homens. (Paiva, 2007; Rousseau (1973 [1762])

Ora, como salientámos ao longo do artigo, o "conhecimento pronto" constitui-se como a base da escravidão intelectual; o conhecimento superficial, orientado cada vez mais por pressupostos pragmáticos, constitui-se como a base da imaturidade cívica e política. A retórica das competências tende a transformar-se hoje pela ótica de meros critérios de empregabilidade. É certo que a escola também não se pode alhear da produção de saberes essenciais às exigências do mundo atual; até porque um tal alheamento seria penalizador sobretudo para as classes mais desfavorecidas, logo tenderia a replicar as desigualdades de base. Isso deverá, no entanto, ser produto de foco maior, como salientámos, de uma "cidadania global inteligente" (Nussbaum, 2010, p. 81), não um fim em si mesmo. Apresentámos, por isso, um modelo pedagógico que, embora orientado pelos pressupostos atuais de educação para o empreendedorismo, permite concebê-la como uma oportunidade para uma pedagogia diferenciada e para uma atuação responsável e holística (e não somente económica) no mundo.

Essa visão pressupõe o entendimento (mais consistente e experiencial) dos valores e das diversas formas de ser e de interagir, bem como de questões como a eficácia, a legitimidade, a integralidade e o exercício de um poder responsável (Wenger, 2009, p. 20); a geração de um sentido de tolerância que não seja sinónimo de indiferença e desconexão, a discussão e prática de um sentido de pluralismo que não seja um mero monólogo entre adaptados e adaptáveis, a construção de um verdadeiro sentido de articulação global e local, basilar, não em uma sociedade da informação, mas da sabedoria e do bem comum (Max-Neef; Smith, 2014).

Em conclusão, um novo paradigma de escola empreendedora para a cidadania pressupõe a assunção de que todos - o porteiro da escola, a funcionária da cantina, o segurança... - são educadores e que a comunidade educativa consubstancia necessariamente um espaço democrático de convívio ético, não uma escola "palavrosa", como afirma Paulo Freire (2001, p. 11), mas, antes, uma escola como espaço público deliberativo (Habermas, 1981) e interventivo. Uma escola não somente como um "lugar em vários mundos", na expressão de Derouet (1992), mas como um lugar de vários mundos, em uma verdadeira policronia de sentidos - da universalidade de princípios e direitos à consideração das desigualdades de situações e à pluralidade de subjetividades no espaço educacional e social. 


\section{REFERÊNCIAS}

Alves, R. A alegria de ensinar. São Paulo: Ars Poética, 1994.

Barnett, R. The limits of competence. Buckingham: Open University Press, 1994.

Bates, I. The competence movement and the National Vocational Qualifications framework. The widening parameters of research. British Journal of Education and Work, Abingdon: Routledge, v. 8, n. 2, p. 5-13, 1995.

Brown, L. M. et al. (Eds.). Competence-based training. A collection of readings. Victoria: Deakin University, 1994.

Coburn, C. E.; Stein, M. K. Communities of practice theory and the role of teacher professional community in policy implementation. In: Honig, M. I. (Ed.). New directions in education policy implementation. Confronting complexity. Albany: Suny Press, 2006. p. 25-46.

Cooper, B. Continuing professional development: a critical approach. In: Fraser, S.; Matthews, S. (Eds.). The critical practitioner in social work and health care. London: Sage Publications, 2008. p. 222-237.

Correia, E. Avaliação externa do Projeto Nacional de Educação para o Empreendedorismo (PNEE). Levantamento Nacional de Dados. Lisboa: CIES; Instituto Universitário de Lisboa (ISCTE-IUL), 20 dez. 2010.

Avaliação externa do Projeto Nacional de Educação para o Empreendedorismo (PNEE). Fase 2 - Realização de Estudos de Caso. Lisboa: CIES; Instituto Universitário de Lisboa (ISCTE-IUL), 4 fev. 2011.

Cuervo, Á.; Ribeiro, D.; Roig, S. Entrepreneurship. Concepts, theory and perspective. Berlin: Heidelberg, 2007.

Delamare-Le Deist, F.; Winterton, J. What is competence? Human Resource Development International, London: Routledge, v. 8, n. 1, p. 27-46, 2005.

Delors, J. et al. Educação, um tesouro a descobrir. Relatório para a UNESCO da Comissão Internacional da Educação para o Século XXI. Brasilia, DF: UNESCO. 2010. Derouet,J.-L. École et justice. De Légalité des chances aux compromis locaux? Paris: Editions Métailié, 1992.

Dewey,J. My pedagogic creed. The School Journal, v. 54, n. 3, p. 77-80, 1897. Disponível em: <http://edweb.sdsu.edu/people/dkitchen/TE655/my_pedagogic_creed.htm>. Acesso em: $1^{\circ}$ set. 2013.

DGIDC - Direção-Geral de Inovação e Desenvolvimento Curricular. Ministério da Educação. Dossier PNEE. Projeto Nacional "Educação para o Empreendedorismo". Lisboa: ME/Equipa de Coordenação do PNEE, dez. 2007.

EC - European Commission. New skills for new jobs. Action now: a report by the expert group on new skills for new jobs prepared for the European Commission. 2010. Disponível em: <http://ec.europa.eu/social/main.jsp?catId=822\&langId=en>. Acesso em: 15 jan. 2012.

FerReIRA, J. S. Entrepreneur XXI. Education for entrepreneurship - new paradigm? International Business and Economics Review, Lisboa: Instituto Superior de Gestão, n. 2, p. 16-29, 2011. 
.; TAPIA, A. Referencial de formação em competências empreendedoras. Lisboa: Instituto de Emprego e Formação Profissional, 2010. Disponível em: <http://www. tree-institute.org/publica/ref\%20formacao\%20compet\%20empreend\%20IEFP.pdf 〉. Acesso em: 10 abr. 2015.

Ferreira, J. S.; Albuquerque, C. Scaling up entrepreneurial education models and processes. Critical issues for success. IBER - International Business and Economics Review, Lisboa: ISG; CIGEST, n. 4, p. 38-54, 2013.

Freire, P. N. Educação e atualidade brasileira. São Paulo: Cortez; Instituto Paulo Freire, 2001.

Gadotti, M. Os mestres de Rousseau. São Paulo: Cortez, 2004.

Habermas, J. (1981). The theory of communicative action: reason and the rationalization of society. Cambridge: Polity Press. v. 1.

Hager, P.; Gonczi, A. Professions and competencies. In: Edwards, R.; Hanson, A.; RAgGat, P. (Eds.). Boundaries of adult learning. London: Routledge; Open University Press, 1996. p. 246-260.

; Beckett, D. Philosophical underpinnings of the integrated theory of competence. Educational Philosophy and Theory, Abingdon: Routledge, v. 27, n. 1, p. 1-24, 1995.

Нескмал, J. The developmental origins of health: models and evidence. Stephen Frankel Lecture. Bristol: University of Bristol, 2011.

Jessup, G. Outcomes. NVQs and the emerging model of education and training. London: Falmer, 1991.

Katz, D.; Kahn, R. L. Psicología social de las organizaciones. Madrid: Trillas, 1989.

Kearney, A. J. Análise aplicada do comportamento. Lisboa: Porto Editora, 2009.

Lave, J.; Wenger, E. Situated learning. Legitimate peripheral participation. Cambridge: Cambridge University Press, 1991.

Lindsey, O. R. Precision teaching: by teachers for children. Teaching Exceptional Children, Thousand Oaks: Sage Publications, v. 22, n. 3, p. 10-15, 1990.

Lum, G. Where's the competence in competence-based education and training? Journal of Philosophy of Education, Wiley Online Library, The Philosophy of Education Society of Great Britain, v. 33, n. 3, p. 403-418, 1999.

Max-Neef, M.; Sмith, P. B. La economía desenmascarada: del poder y la codicia a la compasión y el bien común. Barcelona: Icaria Editorial, 2014.

Medeiros, E. O. (Coord.). A educação como projeto. Desafios de cidadania. Lisboa: Instituto Piaget, 2010.

Melton, R. F. Competence in perspective. Educational Research, Abingdon: Routledge and National Foundation for Educational Science, v. 36, n. 3, p. 285-294, 1994.

Morin, E. Os sete saberes necessários à educação do futuro. 3. ed. São Paulo: Cortez; UNESCO, 2001.

Mosé, V. Desafios da educaşão. CPFL Cultura: Café Filosófico, 2013. Conferência. Disponível em: <www.youtube.com/watch?v=EigUj_d5n80>. Acesso em: 10 abr. 2015. 
Mulder, M. Competence. The essence and use of the concept in ECVT. European Journal of Vocational Training, Thessaloniki (Pylea), Greece: European Centre for the Development of Vocational Training, v. 40, n. 1, p. 5-21, 2007.

Nussbaum, M. C. Not for profit. Why democracy needs the humanities. Princeton: Princeton University Press, 2010.

Crear capacidades. Propuesta para el desarollo humano. Barcelona: Paidós, 2012.

Paiva, W. A. A formação do homem no Emílio de Rousseau. Educação e Pesquisa, São Paulo: USP, v. 33, n. 2, p. 323-333, 2007.

Ritzer, G. The McDonaldization of society: an investigation into the changing character of contemporary social life. USA: Pine Forge Press; Sage Publications, 1996.

Rousseau, J.-J. Emílio ou da educação. 2. ed. São Paulo: Difusão Europeia do Livro, 1973 [1. ed. 1762].

Sen, A. Desenvolvimento como liberdade. Lisboa: Gradiva, 2003.

Sultana, R. G. Competence and competence frameworks in career guidance: complex and contested concepts. International Journal of Education and Vocational Guidance, Europe: Springer, n. 9, p. 15-30, 2009.

WEF - World Economic Forum. Educating the Next Wave of Entrepreneurs - Unlocking entrepreneurial capabilities to meet the global challenges of the 21st Century. A report of the Global Education Initiative. 2009. Disponível em: <http://www.weforum.org/ pdf/GEI/2009/Entrepreneurship_Education_Report.pdf>. Acesso em: 15 jan. 2012.

Wenger, E. Social learning capacity. Four essays on innovation and learning in social systems. In: VAle, A. et al. (Eds.). Social innovation: new perspectives. Lisboa: GEP/ MTSS, 2009.p. 15-35.

Wolff, J.; De-Shalit, A. Disadvantage. Oxford: Oxford University Press, 2007.

\section{SOBRE OS AUTORES}

Cristina Pinto Albuquerque é doutora em política social e trabalho social pela Universidade de Fribourg (Suíça). Professora da Universidade de Coimbra (Portugal).

E-mail: crisalbuquerque@fpce.uc.pt

José Soares Ferreira é especialista em marketing pela Universidade Católica (Portugal). Presidente do Tree Institute - Associação para o Desenvolvimento Económico, Social e Humano (Portugal).

E-mail: jose@tree-institute.org

Graça Brites é licenciada em estudos europeus pela Universidade de Lisboa (ULisboa). Membro permanente do Instituto Universitário de Lisboa (ISCTE-IUL).

E-mail:mglcs@iscte.pt 